\title{
Propuesta teórica: Implementación de elementos del modelo de inmersión para su adaptación a nuestro contexto. Planteamientos para su aplicación y evaluación
}

\section{Theoretical proposal: Implementation of the elements of the immersion model for its adaptation to our context. Proposals for their application and evaluation}

\author{
Jazmin Meneses Vera ${ }^{a}$
}

\begin{abstract}
:
The dual immersion model that is carried out in some of the schools in the United States has been implemented with great success in the achievement of bilingualism among its students, so Ibelieve that it is possible to retrieve and evaluate some of the procedures and the methodology that place within this. It would only be necessary to make the adjustments so that it fits in our context for our students to acquire the necessary skills in the effective command of both languages, to this end I suggest the implementation and evaluation of a number of proposals based on this programme.
\end{abstract}

Keywords:

Bilingual; culture; Two way immersion;; language;

\section{Resumen:}

El modelo de inmersión dual que se trabaja en algunas de las escuelas de Estados Unidos ha sido implementado con gran éxito al lograr el bilingüismo en sus estudiantes, por lo que considero que es posible rescatar y valorar algunas de las prácticas que se llevan a cabo dentro de esta metodología de trabajo, realizando los ajustes correspondientes a nuestro contexto a fin de lograr que nuestros alumnos adquieran las competencias necesarias en el manejo eficaz de ambos idiomas, para ello sugiero la aplicación y evaluación de una serie de propuestas basadas en este programa.

\section{Palabras Clave:}

Bilingüe; cultura; Inmersiòn dual; lenguaje;

\section{INTRODUCTION}

En un mundo tan dinámico y lleno de información proveniente de muchos países y en diversos idiomas, el hecho de ser bilingüe abre enormes posibilidades a las personas que tienen esta habilidad, no solo en el ámbito educativo, sino también en lo laboral, cultural, social etc. En muchas escuelas privadas de nuestro país se trabaja de forma bilingüe con diversas metodologías y esto supone importantes beneficios en sus estudiantes, sin embargo, nunca está de más conocer y agregar algunos elementos que puedan fortalecer las prácticas educativas y el rendimiento del alumnado, es por ello que desde mi experiencia, me gustaría plantear algunas propuestas, que sí bien algunas de ellas tal vez ya se utilizan, quizá cabe la iniciativa de evaluar, replantear o ajustar lo que se considere adecuado.

En el marco de colaboración por el Convenio SEPHLouisiana, tuve la oportunidad de participar como maestra de intercambio e integrarme como titular de Español de primer grado en Fairview Elementary School, una escuela primaria ubicada en la ciudad de Lake Charles Louisiana, en la cual se comenzó a trabajar el progr ama TWO WAY IMMERSION o de inmersión dual, durante el ciclo escolar 2019-2020

\section{INMERSIÒN DUAL}

Muchos son los esfuerzos del gobierno norteamericano por proveer a los estudiantes de oportunidades de desarrollo y de incrementar las posibilidades de interacción con personas de diversas partes del mundo. Los maestros que llegamos a atender estos grupos proveníamos de países como Costa Rica, España, Francia, Bélgica y por supuesto de México. Esto genera un amplio bagaje no solo de lenguas, sino también de cultura y tradiciones. Lo cual resultó ser una experiencia gratificante y enriqueced ora en muchos sentidos.

La propuesta de educación dual, se fundamenta en la teoría de integrar a los alumnos inmigrantes con la mayoría y conseguir que, siguiendo una instrucción en dos lenguas, ambos grupos sean bilingües y que, además, desarrollen actitudes de respeto hacia otras culturas (Verde,2013)

Los niños migrantes provenientes de Latinoamérica se han enfrentado a diversas problemáticas, para llegara la unión americana, como la ruptura de sus familias, la situación

\footnotetext{
${ }^{a}$ Jazmin Meneses Vera, Secretaría de Educación Pública de Hidalgo, https://orcid.org/0000-0003-4165-0918 Email: jazminmeve@hotmail.com
} 
económica, el racism, entre muchos otros y sí aunado a todo lo anterior se encuentran con la barrera del idioma, vaya que se vuelve muy complicado el poder tener un adecuado rendimiento escolar. Es por ello que me parece una opción muy atinada implementar programas como és te a fin de apoyar un poco a estas comunidades escolares.

En otras escuelas se tiene el apoyo de programas como ESL (English as a second Language) en los que monitorean y asesoran a aquellos alumnos que no hablan inglés y que se incorporan a la escuela americana. Se les proporciona atención individual, en espacios fuera de sus clases para hacer las adaptaciones necesarias, a fin de que el alumno pueda progresar en ambos idiomas.

En este programa, no es necesario el ESL, ya que se caracteriza por iniciar en preescolar con un $90 \%$ del tiempo de instrucción académica en español con maestros bilingües originarios de países hispanohablantes. El maestro titular se encarga de impartir Matemáticas, Sociales, Ciencias y Lectoescritura. Y el $10 \%$ restante de las clases lo reciben de un maestro americano en inglés, durante una hora diaria, además de las clases de música, pintura y educación física que también son impartidas en inglés una vez por semana cada una.

Es de gran importancia comenzar con este proyec to desde edades tempranas, ya que Se considera que cuando el estudiante construye una buena base en su primer idioma, es capaz de transferir estas habilidades y conocimientos a la L2 hasta alcanzar la (bi)alfabetización. (Haldòn 2015)

Al pasar a primer grado ahora la enseñanza en español se reduce al $80 \%$ del tiempo y la maestra de inglés incrementa su estancia en el grupo al $20 \%$. Y lo mismo sucede al pasar a segundo grado el tiempo de las asignaturas en español disminuyen al $70 \%$ escolar, mientras que en inglés sube al $30 \%$ y así hasta llegar al quinto grado, momento en el cual se pretende que todos los alumnos inscritos en esta clase, hayan alcanzado un nivel aceptable de dominio de ambos idiomas y que tengan ahora el $50 \%$ de enseñanza en español y el otro $50 \%$ en inglés.

En la actualidad, la enseñanza bilingüe dual no solo disfruta de una reconocida reputación entre la comunidad educativa estadounidense sino que también cuenta con el respaldo de un numeroso y activo cuerpo de investigadores (Serrano, 2020)

Los grupos se integran de forma heterogénea, y al tener niños americanos tomando clases en español (una lengua que no dominan y que además deben comprender para entender sus asignaturas) y niños latinos originarios de diversos lugares, (que tampoco comprenden el inglés en su totalidad) esto posibilita el apoyo y utilización frecuente de ambas lenguas. También supone un esfuerzo por parte de los padres de familia que deben apoyar a sus hijos en tareas en ambos idiomas sin ser expertos en ello.
Dentro de la escuela también se refuerza la utilización de español e inglés simultáneamente, con carteles y etiquetas colocados en todos los espacios escolares (baños, biblioteca, dirección, cafetería etc.) con la inten ción de recordar constantemente el uso de ambos idiomas, distinguiendo en color rojo para español y azul para inglés además de fortalecer aspectos gramaticales de las dos lenguas. Durante los recreos o almuerzos también se fomenta el uso de los dos idiomas. En la biblioteca hay libros y material didáctico en español y también en inglés para que se pueda contar con estas herramientas de soporte.

Las actividades realizadas en el campus van desarrollándose de tal modo que se cumpla con el propósito del día. Desde el momento en el que los alumnos llegan son recibidos por maestras que los conducen a la cafetería para tomar el desayuno, posteriormente van rumbo al salón de clases y los niños pueden tomar libros en cualquiera de los idiomas mientras comienzan las clases. Al sonar el timbre de inicio de actividades los estudiantes entran y toman sus lugares mientras escuchan en el altavoz los anuncios de dirección primero en inglés y posteriormente en español.

Por la mañana es el momento en el que se refuerza lo que tiene que ver con la gramática y la escritura en español, los niños participan identificando los fonemas y palabras que recientemente han descubierto. Al terminar, la maestra realiza una lectura grupal que es proyectada para poder visualizar el texto e ir siguiéndolo. Los alumnos tienen oportunidad de tomar el libro de su agrado y sentarse a leer con un compañero que no habla el mismo idioma para comentar su lectura, intentando que ambos puedan comunicase en español. Mientras la maestra trabaja en lectura individual con los alumnos que ese día deban registrar avance.

Enseguida llega la maestra americana, quien desde que entra, hace que el ambiente se transforme totalmente a inglés. Se repasan los temas de matemáticas, ciencias y sociales vistos el día anterior, pero ella lo hace de tal forma que ahora deban practicar todo lo aprendido en inglés. Posteriormente van a tomar el lunch, y al terminar de comer van al patio a recreo. Estos periodos son clave para que los alumnos pongan en práctica la comunicación efectiva con todos los compañeros, ya que, al encontrarse en un ambiente un poco más libre, pueden expresarse y combinar lo que saben, sin reparo en sí lo que dicen tiene coherencia o sí gramaticalmente es correcto, simplemente se expresan tratando de comunicar sus ideas o necesidades.

Cuando regresan al salón es hora de continuar con matemáticas, ciencias y sociales, trabajando en equipos con los centros establecidos, en los cuales se van alternando para practicar en diversas actividades. Cuando llega el momento de la clase extra (música, pintura, educación física), se da la siguiente oportunidad para hacer uso de las habilidades en inglés. Los niños suelen ayudarse a comunicar sus ideas cuando alguno siente que no puede 
hacerlo por sí mismo, pero esto sin duda es una ocasión para seguir aprendiendo.

La hora de salida y regreso a casa también son ocasiones de seguir interactuando con otros niños y poder platicar en cualquiera de los dos idiomas. En los otros grupos de Elementary sucede algo muy similar, solo con las variantes de proporción de inglés-español. En los siguientes niveles como Middle School y High School la dinámica de trabajo es diferente pero los alumnos siempre pueden participar de actividades y clases de español.

Diversas investigaciones muestran que la enseñanza bilingüe aporta importantes beneficios al desarrollo del estudiante, entre los que destacan: mejo res resultados en exámenes estandarizados, dado que el alumno puede procesar la información en dos vías y con dos modalidades de aprendizaje. Esto permite que el pens amiento de estos niños, sea más creativo y flexible comparado con quienes solo toman clase en una lengua. Así mismo se ha observado que los alumnos bilingües logran la solución de problemas de una forma más eficiente y que su nivel cognitivo también incrementa de forma importante al mejorar su razonamiento y compresión.

Desde el enfoque humanista es muy loable que este tipo de programas coadyuven a la integración social, ya que favorecen un entorno más inclusivo y un desarrollo progresivo que fortalece los vínculos a su alrededor y permite establecer relaciones de amistad que ayudan no solo al alumno sino también a sus familiares.

La interculturalidad es otro de los elementos que beneficia a estas comunidades estudiantiles, ya que se privilegian actitudes como el respeto y la tolerancia; además de aprender a reconocer y valorar la diversidad y tener así la posibilidad de compartir ideas, tradiciones, costumbres etc. con personas de diversos lugares.

En cuanto a aspectos afectivos o emocionales, la autoestima de las personas que logran comunicarse en dos idiomas también se beneficia, al poder expresar sus necesidades y comunicarse con sus compañeros. Los chicos bilingües se vuelven más populares, seguros de sí mismos y confían en sus propias capacidades, por lo tanto, al conseguir logros en el ámbito académico, éstos les motivan a continuar esforzándose para sentirse parte del grupo.

El conocimiento de más de una lengua enriquece la visión que el hombre tiene del mundo y contribuye a fomentar la tolerancia y la comprensión entre personas de distintos orígenes lingüísticos y culturales. (Aragòn, 2007).

\section{PROPUESTAS DE TRABAJO}

Por este motivo, considero que algunas de las formas de trabajo que ya se tienen establecidas en escuelas bilingües, se pueden apoyar de las propuestas que a continuación hago, con la única finalidad de que puedan ser evaluadas para su implementación en nuestro contex to
1.- Comunidad de aprendizaje bilingüe: Aunque aquí no tenemos tanta población angloparlante, sería muy bueno que se pueda establecer un programa entre instituciones americanas y escuelas mexicanas, a fin de lograr que cada alumno tenga la oportunidad de preguntar, repasar o estudiar los temas vistos con un compañero de otro país, mediante el uso de plataformas digitales que puedan favorecer esta comunicación.

2.-Intercambio cultural entre instituciones: Es importante que al mismo tiempo se destinen espacios que promuevan la cultura y tradiciones de la escuela, lugar o país con el que se tenga el convenio, y al menos una vez al mes presentar un video o explicación para intercambiar y conocer mientras se fortalece el uso de los dos idiomas.

3.-Adecuaciòn de talleres, espacios culturales y clases extra que propicien el uso de ambos idiomas: La iniciativa aquí trata de que en la escuela donde normalmente el alumno toma su taller de guitarra o su entrenamiento de básquetbol, éstas puedan ser totalmente en inglés, con la intención de practicar fuera del contexto del aula.

4.-Incremento gradual del tiempo de práctica de idiomas: Normalmente en las escuelas bilingües tienen horarios específicos para idiomas, lo recomendable sería que materias como ciencias, matemáticas o sociales puedan ser impartidas por profesores bilingües para poder ampliar el vocabulario y tener mayor tiempo de práctica en inglés.

5.- Planeación de secuencias didácticas que motiven la investigación en otra lengua: Cualquier asignatura puede preparar materiales o presentaciones atractivas, lo ideal sería que el alumno tenga la oportunidad de ir más allá e investigar no solo para tarea, sino por el deseo de saber más, por lo que se le pueden hacer sugerencias, de páginas, blogs, o canales en inglés, donde puedan acceder y seguir aprendiendo.

6.-Creaciòn de espacios pedagógicos ajustados al programa de inmersión: Los salones, biblioteca, gimnasio, dirección etc. pueden ser lugares donde los alumnos sigan observando indicaciones, información y decoración en inglés.

7.-Acercamiento a materiales de trabajo en otra lengua: Todos los materiales audiovisuales en inglès que puedan tenerse al alcance, serán de gran utilidad para este propósito.

8.- Fomentar la participación estudiantil en competencias, actividades sociales y culturales extraescolares que promuevan la interacción con otra lengua: Cuando la escuela organiza actividades de esta naturaleza, suelen ser muy atractivas para la comunidad escolar y con la intención de poder participar, harán lo necesario. Por ello me parece que tanto convocatorias, información e ingresos pueden ser en inglés para motivar también la práctica del idioma en otro contexto.

9.-Enfoque transversal que desarrolle las competencias lingüísticas de los alumnos: El objetivo de la escuela bilingüe es dotar al alumno de las herramientas n ecesarias 
para que sea competente en dos idiomas, por ello propongo el trabajo por proyectos que permitan vincular las divers as asignaturas en favor de reducir la carga de tareas, pero al mismo tiempo se consoliden las destrezas en el uso de los dos idiomas.

10.- Implementación de clases de reforzamiento con objetivo dual: A aquellos alumnos que requieren de una asesoría para profundizar en un tema, esta puede ser ofrecida en inglés con la intención de buscar que el alumno pueda procesar la información recibida previamente, pero ahora escuchándola de otro maestro, en otra lengua y tal vez con otra perspectiva.

11.-Capacitación del personal docente para el trabajo con esta metodología. Ninguna de las recomendaciones anteriores sería posible, sí el cuerpo docente desconoce el proyecto de inmersión dual; por lo tanto, es necesario que toda la plantilla reciba la orientación necesaria para poder desarrollar un trabajo que dé resultados.

12.-Evaluaciones que promuevan la certificación de alumnos en otra lengua. El objetivo primordial, será siempre que los alumnos puedan alcanzar los conocimientos necesarios para obtener una certificación oficial del idioma inglés, por ello, la escuela bilingüe debe garantizar que el alumno ha sido preparado con altos estándares que le permitirán aprobar y hacer uso de esta habilidad.

\section{CONCLUSIONES}

Evidentemente los contextos de México y Estados Unidos son diferentes, y la situación del país vecino dista mucho de lo que en otros lugares se vive, sin embargo, al observar los beneficios que puede proveer la aplicación de este tipo de metodologías en los estudiantes, en lo referente a la enseñanza de idiomas cabe plantearse la posibilidad de integrar algunos elementos susceptibles de ser utilizados para la aplicación en las escuelas. Tales como la creación de un ambiente pluricultural.

En estos días donde la tecnología ha venido a revolucionar nuestras vidas y nos permite acercarnos a cualquier lugar del planeta, podemos pensar en la posibilidad de no solo cerrarse al espacio del aula o al territorio nacional, sino de expandir nuestra labor más allá de las fronteras, conociendo personas de otros lugares con las que podamos llevar a la práctica algunas actividades de aprendizaje. La tec nología puede ser una herramienta que nos permita mayor interacción y acercamiento a otras culturas. Es importante rescatar aquellos aspectos que puedan ser adaptados en nuestro país, considerando las condiciones específicas que imperan en nuestro entorno.

\section{REFERENCIAS}

[1] Aragón-Méndez, María del Mar(2007) La ciencias experimentales y la enseñanza bilingüe Revista Eureka sobre Enseñanza y Divulgación de las Ciencias, vol.4,núm.1, enero, 2007,p 1 pp. 152- 175 https://www.redalyc.org/pdf/920/92040110.pdf.
[2] Haldón Arasa Lorena (2015) La enseñanza de español en Estados Unidos dentro del Modelo de Inmersión Dual Gómez y Gómez._RedELE revista electrónica de didáctica del español lengua extranjera ISSN: 1571-4667, número 27

https://www.culturaydeporte.gob.es/dam/jcr:3091c0a 1-1127-401a-b9eadc2012198f13/2015-redele-27-7-lorena-haldon-arasa-pdf.pdf;

[3] Serrano Sanchez Josè Luis (2020) Aprendizaje de un segundo idioma apoyado en tecnologías digitales: una revisión Sistemática Vol. 21 (2020): Education in the Knowledge Society, Artículos, Pág.13 https://digitum.um.es/digitum/handle/10201/95104

[4] Verde Peleato Irene (2013) Políticas y modelos de educación bilingüe en la atención a la diversidad lingüística en Estado. Revista de Educación, 360. Enero-abril 2013 pp. 685-696 Universidad de Valencia. Facultad de Filosofía y Ciencias de la Educación. Valencia, España http://repositorio.minedu.gob.pe/handle/20.500.12799/961 